\title{
Transient Liquid Phase Bonding of Semi-Solid Metal 7075 Aluminum Alloy Using ZA27 Zinc Alloy Interlayer
}

\author{
Chaiyoot Meengam ${ }^{1, *}$, Yongyuth Dunyakul ${ }^{2}$, Dech Maunkhaw ${ }^{2}$ and Suppachai Chainarong ${ }^{1}$ \\ 1 Department of Engineering, Songkhla Rajabhat University, Songkhla 90000, Thailand; \\ Suppachai.ch@skru.ac.th \\ 2 Department of Industrial Engineering, Rajamangala University of Technology Srivijaya, \\ Songkhla 90000, Thailand; Dyongyuth@gmail.com (Y.D.); dechmaunkhaw@yahoo.com (D.M.) \\ * Correspondence: Chaiyoot.me@skru.ac.th; Tel.: +66-074-260-200; Fax: +66-074-260-230
}

Received: 6 July 2018; Accepted: 8 August 2018; Published: 13 August 2018

\begin{abstract}
Transient Liquid Phase Bonding (TLPB) process of semi-solid metal 7075 aluminum alloys (SSM7075) using $50 \mu \mathrm{m}$ thick of ZA27 zinc alloys as interlayers for the experiment were carried out under bonding temperatures of 480 and $540{ }^{\circ} \mathrm{C}$ and bonding times of 30, 60, 90 and $120 \mathrm{~min}$ respectively. In the bonding zone, the semi-solid state of ZA27 zinc alloy interlayers were diffused into the SSM7075 aluminum alloy. Examination of the bonding zone using Scanning Electron Microscope (SEM) and Energy-dispersive X-ray spectroscopy (EDS) showed that the precipitation of the intermetallic compound of $\eta(\mathrm{Zn}-\mathrm{Al}-\mathrm{Cu}), \beta\left(\mathrm{Al}_{2} \mathrm{Mg}_{3} \mathrm{Zn}_{3}\right), \mathrm{T}^{\prime}\left(\mathrm{Zn}_{10} \mathrm{Al}_{35} \mathrm{Cu}_{55}\right)$ and $\mathrm{MgZn}_{2}$ were formed in the bonding zone. The better homogenized microstructure in the bonding zone was formed when increasing bonding time and bonding temperature. The highest bonding strength was recorded at $17.44 \mathrm{MPa}$ and average hardness was at $87.67 \mathrm{HV}$ with the bonding time of $120 \mathrm{~min}$ and temperature at $540{ }^{\circ} \mathrm{C}$. Statistically, the coefficient of determination analysis of bonding strength data was at $99.1 \%$.
\end{abstract}

Keywords: Transient Liquid Phase Bonding; SSM7075 Aluminum alloys; ZA27 Zinc Alloy

\section{Introduction}

Transient Liquid Phase (TLB) Bonding is another interesting welding process. This is a diffusion bonding in the liquid stage [1] in which the bonding zone will partially become liquid due to the property of the materials which can be soldered at low melting temperature [2,3]. The advantages of this TLP bonding are lower bonding temperature, lower bonding pressure, easier surface preparation than solid-state diffusion bonding, and it can weld between materials with distinct chemical properties or dissimilar joint materials [4-6]. Moreover, this TLP bonding technique offers a better oxide destruction mechanism in bonding area traditional aluminum alloy welding process [7]. However, there are still some limitations for the TLP bonding process due to the complexity in welding and long bonding time. Generally, TLP bonding was used in high quality weld applications, such as sandwich materials or fuel tanks [8]. Aluminum alloy has often been used with this type of welding to produce a product. The 7075 aluminum alloy casting has been used in aircraft industries, automotive industries, and electronic industries [9]. And, the presence of microstructure in 7075 aluminum alloy was improved in order to increase the strength of mechanical properties. The Gas Induce Semi-Solid (GISS) process is another technique used to formed semi-solid metal 7075 aluminum alloy (SSM7075) [10]. So, finding a suitable welding process for semi-solid casting material is quite challenging because the main problem for the traditional SSM7075 aluminum alloy welding process is that oxide film can form in the bonding zone. However, the advantage of the TLP bonding process is a reduction in oxide 
film formation to support better diffusion by allowing the atoms to spread and interchange between materials in the liquid state [11]. Moreover, the TLP bonding process is protected by a well-controlled gas atmospheric chamber, which affects the mechanical properties of samples after welding [12]. The TLP bonding of SSM7075 aluminum alloy using ZA27 zinc alloy as filler metal can diffuse faster and more complete because $\mathrm{Zn}$ and $\mathrm{Al}$ is a main ingredient in ZA27 zinc alloy. On the other hand, SSM7075 aluminum alloy also has $\mathrm{Al}$ and $\mathrm{Zn}$ as main ingredients, in which the basis of chemical compositions are similar due to solvency of the eutectic phase and this will encourage successful TLP bonding.

The parameters for the TLP bonding process between SSM7075 aluminum alloy and ZA27 zinc alloy interlayer are bonding time, bonding temperature, bonding pressure, preparation surface sample, etc. In this experiment, we focus on the effect of eutectic formation and evaluate the macrostructure and microstructure on bonded joints, examined by scanning electron microscopy and mechanical properties tests.

\section{Materials and Methods}

The main concept idea in research is to diffuse two different states of samples SSM7075 aluminum alloy (solid state) and ZA27 zinc alloy (liquids state during welding). These two materials share similar compositions. This TLPB in argon atmosphere will minimize aluminium oxide $\left(\mathrm{Al}_{2} \mathrm{O}_{3}\right)$ and zinc peroxide $\left(\mathrm{ZnO}_{2}\right)$ film formation which leads to better diffuse and to reduce the welding time of samples. Moreover, this is also a new welding technique for SSM7075 aluminum alloy semi-solid cast aluminum alloy.

\subsection{Materials}

The material used in this study was SSM7075 aluminum alloy, which contains aluminium, zinc and magnesium as the main ingredients and the chemical composition is shown in Table 1, with a melting point at $660^{\circ} \mathrm{C}$ and tensile strength at 207.08 MPa (As cast). The SSM7075 aluminum alloy obtained from GISSCO company limited (Samut Sakhon, Thailand) was formed by Gas Induced Semi-Solid (GISS) Technique which is a semi-solid casting technique under casting temperature at $640{ }^{\circ} \mathrm{C}$ and nitrogen gas flowing through porous graphite for $10 \mathrm{~s}$ resulting in the grain structure forming as a globular shape. The microstructure of SSM7075 aluminum alloys includes $\alpha$-aluminum matrix and $\mathrm{MgZn}_{2}$ eutectic phase with the particle grain size at 20-25 $\mu \mathrm{m}$. The filler metal used in this experiment was ZA27 zinc alloy, which contains aluminum and copper as the main ingredients. The chemical composition is shown in Table 1 and it has a melting point of $399^{\circ} \mathrm{C}$ and tensile strength of $125 \mathrm{MPa}$.

Table 1. Chemical composition of SSM7075 aluminum alloy (mass fraction \%).

\begin{tabular}{ccccccccccc}
\hline Element & Zn & Mg & Cu & Fe & Cr & Mn & Si & Ni & Others & Al \\
\hline A1 7075 & 6.08 & 2.5 & 1.93 & 0.46 & 0.19 & - & - & - & 0.45 & Bal. \\
ZA27 & 89.3 & 0.82 & 3.22 & 0.01 & - & 0.91 & 0.81 & 0.05 & - & 4.20 \\
\hline
\end{tabular}

\subsection{Experimental Procedures}

The SSM7075 aluminum alloy was prepared as a cylindrical shape with $12 \mathrm{~mm}$ in diameter and $45 \mathrm{~mm}$ long, and the size of ZA27 zinc alloy was prepared as a filler metal disk with $12 \mathrm{~mm}$ in diameter and $50 \mu \mathrm{m}$ thick. This was used as an interlayer with butt-welded joints. The surface of the sample was polished by grinding surfaces with $\mathrm{P} 400$ grit $\mathrm{SiC}$ paper (Hitachi, Tokyo, Japan) and cleaned in acetone in order to eliminate the dirt. Then, ZA27 zinc alloy filler metal disk was kept in ethanol to prevent surface oxidation effects before starting the TLP bonding process. After the specimen preparation step, specimens were put onto the constant pressure side in the axial direction and the ZA27 zinc alloy filler metal disk was clamped in between SSM 7075 aluminum alloy. In the experiment, parameters used for bonding temperature in the chamber were set at 480 and $540{ }^{\circ} \mathrm{C}$, bonding time at $30,60,90$ and 
$120 \mathrm{~min}$, bonding pressure constant at $3.4 \mathrm{MPa}$ and these were performed in argon gas atmosphere at $6 \mathrm{~L}$ per minute to prevent oxygenation during TLP bonding process. The TLP bonding principle is shown in Figure 1.

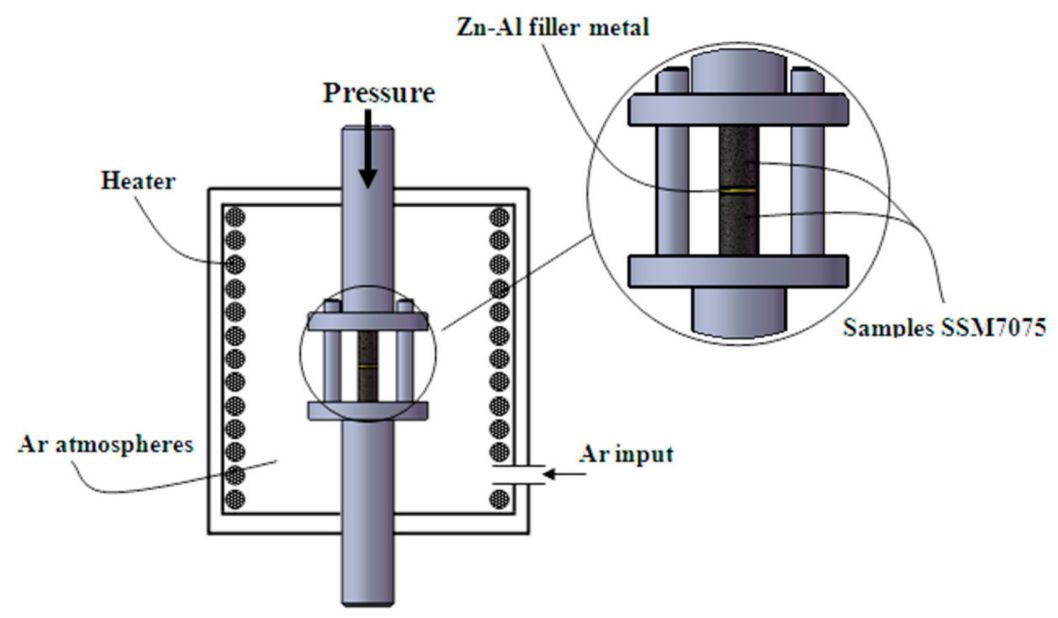

Figure 1. A schematic view of the principle TLP bonding process.

\subsection{Mechanical Testing and Metallurgy Analysis}

The samples were taken to the lathe machine (Jet, La Vergne, TN, USA) for a bond strength test according to American Society for Testing of Materials standard (ASTM E8M-04). The bond strength test was performed under room temperature and was carried out at a crosshead speed at $1.67 \times 10^{-2} \mathrm{~mm} / \mathrm{s}$ with universal testing machine brand LLOYD model EZ50 (MSI-Viking Gage, Duncan, SC, USA). Finally, vicker's microhardness was conducted on Future-Tech model FM-700e (FUTURE-TECH CORP, Kanagawa, Japan). After TLP bonding, the samples were cut by a saw and polished by SiC paper at P320, P400, P600, P800, P1000 and P1200 grit respectively. Then, they were polished with alumina powder at 5, 3 and $1 \mu \mathrm{m}$, and finally etched with Keller's reagent (ES Laboratory, Glendora, CA, USA). (The ingredients for Keller's reagent, such as $190 \mathrm{~mL} \mathrm{H}_{2} \mathrm{O}, 5 \mathrm{~mL} \mathrm{HNO}, 3 \mathrm{~mL}$ $\mathrm{HCl}, 2 \mathrm{~mL} \mathrm{HF}$ and distilled water) to investigate the structure. The microstructure analysis was carried out by using a light optical microscope (Olympus model BH2-UMA) (Olympus Co., Ltd., Bangkok, Thailand) and quantitative chemical composition analysis was performed by an electron microscope (FEI-Quanta model 400) (ThermoFisher, Hillsboro, OR, USA).

\section{Results and Discussion}

\subsection{Results of Microstructure in Bonded Joint}

TLP bonding of SSM7075 aluminum alloy used ZA27 zinc alloy interlayer; it was found that the bonding zone had diffused for the element $\mathrm{Zn}$ atom, which is a primary zinc alloy element from ZA27 due to high concentration. Figure 2 shows the microstructure in the bonding zone from a Scanning Electron Microscope (SEM) (Olympus Co., Ltd., Bangkok, Thailand) photograph with magnification power at $50 \times$ from bonding temperature at $480{ }^{\circ} \mathrm{C}$ and bonding time at $30 \mathrm{~min}$. The results show diffusion of alloying elements of ZA27 zinc alloy to SSM7075 aluminum alloy; this is caused by the bonding temperature and bonding time. The lower bonding temperature and shorter bonding time they are, the larger voids are formed [13]. The voids that happened in the bonding zone induce elimination of incomplete welding. Moreover, voids are longitudinally parallel in the bonding zone. However, when bonding temperature and bonding time are appropriate, these voids will be eliminated with diffusion of atoms leading to homogenous in bonding zone. The bonding temperature is the main factor that affects the formation of the microstructure. It is noteworthy that in SSM7075 aluminum alloy, $\alpha$-Al phase precipitation was observed. Likewise, $\mathrm{MgZn}_{2}$ phase precipitation as 
well, but it has a smaller particle appearance and distribution in the $\alpha$-Al phase. The diffusion of alloying element in ZA27 zinc alloy around the bonding zone shows the rapid diffusion of Zn element $(\beta+\eta$-phase $)$ as shown in Figure $2 a$, which the formation of $\beta+\eta$-phase can be analyzed by binary Al-Zn equilibrium phase diagram shown in Figure 3. The microstructure shows that $\beta+\eta-p h a s e$ formation from bonding time and bonding temperature it resulted $\beta\left(A_{12} M_{3} Z n_{3}\right)$ phase formation is supersaturated to $\beta^{\prime}$-phase [14,15]. Meanwhile, the $\eta(\mathrm{Zn}-\mathrm{Al}-\mathrm{Cu})$ phase merged to $\beta$-phase formation as well, by forming into $\eta^{\prime}$-phase and gradually diffusing to the border of the voids leading to a slowly voids elimination mechanism shown in Figure $2 b$. However, after TLP bonding, we found a crystal of atoms changes and the shrinkage of ZA27 zinc alloy causes the cracks in bonding zone shown in Figure 2c, which affects the bonding strength properties at the joint area.

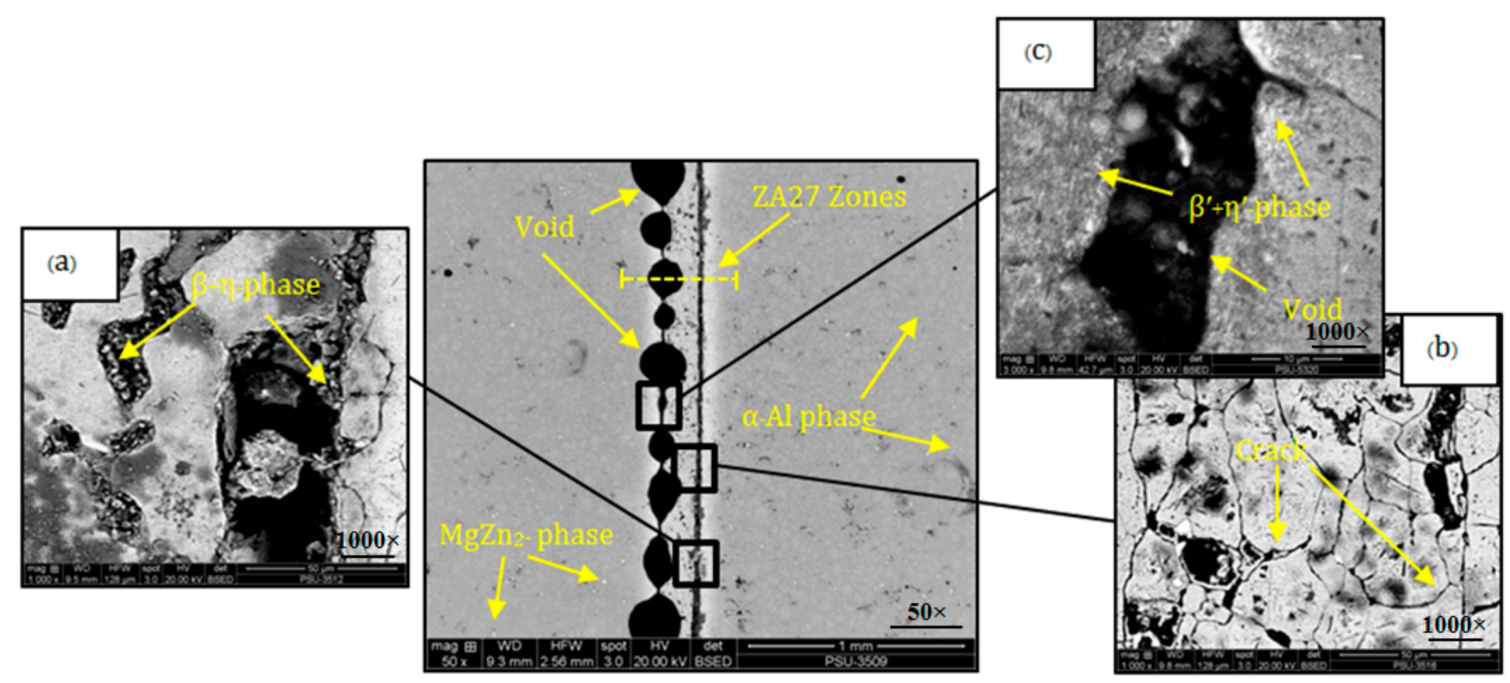

Figure 2. Microstructure of the cross-section of the joint bonded by SEM from bonding temperature at $480{ }^{\circ} \mathrm{C}$ and bonding time at $30 \mathrm{~min}$, (a) the right border between ZA27 interlayer and SSM7075; (b) the middle area of ZA27; (c) the left border between SSM7075 and ZA27 with void.

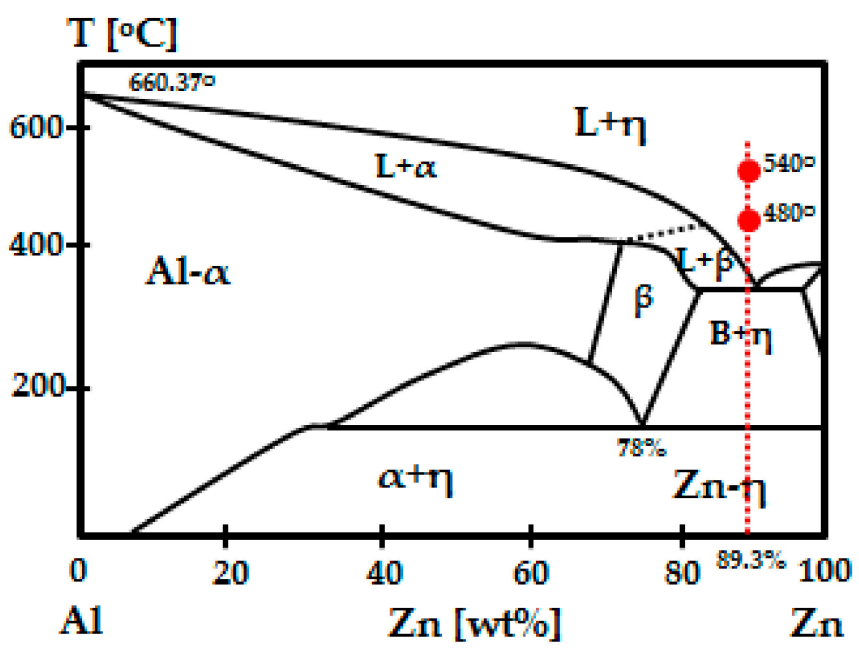

Figure 3. Binary Al-Zn equilibrium phase diagram.

It is noteworthy that the TLP bonding process can easily reduce the number of $\mathrm{Al}_{2} \mathrm{O}_{3}$ and $\mathrm{ZnO}_{2}$ films per area [7]. These two factors-bonding temperature and bonding time-generate a higher bonding temperature reaching $480^{\circ} \mathrm{C}$, which is over the melting point of ZA27 zinc alloy. This is above the liquidus line (evaluated by the binary Al-Zn equilibrium phase diagram shown in Figure 3) and 
turn ZA27 zinc alloy into liquid state. The atom in liquid status has more activation energy than the atom in solid status which allows atoms to move easily. The diffusion rate follows Fick's second law of diffusion, as shown in Equation (1).

$$
\frac{\partial c}{\partial t}=D \frac{\partial^{2} c}{\partial x^{2}}
$$

where $\partial c / \partial t$ is the change in the solute concentration (wt \%) with the time (second) at a given position in the substrates, representing isothermal solidification rate; $D$ is the diffusion coefficient; and $\partial^{2} c / \partial x^{2}$ is the change in concentration gradient with distance [16]. Another factor is caused by the protection with argon gas atmosphere during TLP bonding. The formation of oxide film during TLP bonding was from the incorporation of oxygen to metals and resulted in poor quality TLP bonding samples. Therefore, argon gas will eliminate the oxygen reaction leading to the high efficacy of the joints.

Figure 4 shows the microstructure in the bonding zone with SEM photograph at 50X magnification power from bonding temperature at $540{ }^{\circ} \mathrm{C}$ and bonding time at $120 \mathrm{~min}$. The increase in bonding temperature and bonding time clearly affects the microstructural changes. The dispersion of ZA27 zinc alloy in the bonding zone became wider, which shows that atoms of Zn elements are able to move and diffuse further, when compared to a bonding temperature at $480{ }^{\circ} \mathrm{C}$. The joint microstructure in the bonding zone completely formed, as shown in Figure $4 \mathrm{a}$. The void was eliminated and remained in very small quantities, as shown in Figure 4c, which is a good tendency for tensile strength. It is noteworthy that at high bonding temperature in SSM7075 aluminum alloy (around the bonding zone), Zn elements were recrystalized forming $\mathrm{T}^{\prime}\left(\mathrm{Zn}_{10} \mathrm{Al}_{35} \mathrm{Cu}_{55}\right)$ phase (black particles are $\mathrm{T}^{\prime}$-phase) [14,15]. The increase of bonding temperature and bonding time affect the precipitation of the $\mathrm{MgZn}_{2}$ phase, resulting in smaller particles and more excellent distribution, as shown in Figure $4 \mathrm{~b}$. Moreover, the $\mathrm{MgZn}_{2}$ phase in SSM7075 aluminum alloy combined with $\beta+\eta$-phase led to $\mathrm{MgZn}_{2}$ and $\beta+\eta$-phase in liquids status allowing atoms to freely move.

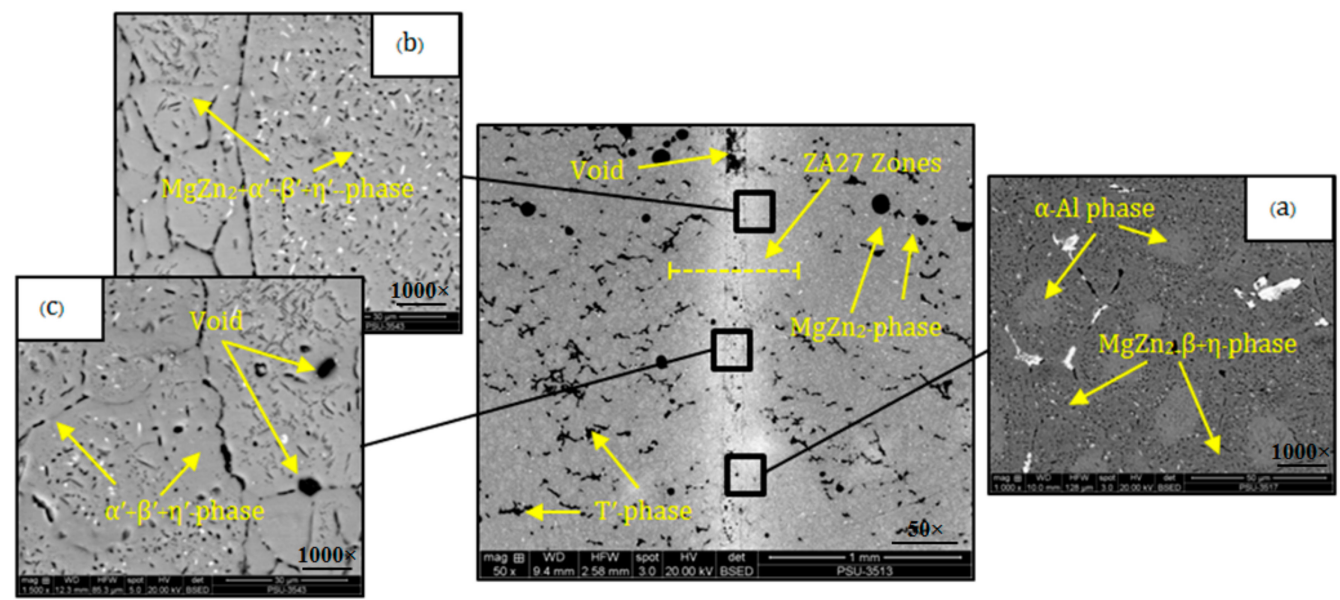

Figure 4. Microstructure of the cross-section of the joint bonded by SEM from bonding temperature at $540{ }^{\circ} \mathrm{C}$ and bonding time at $120 \mathrm{~min}$, (a) the right border between ZA27 interlayer and SSM7075; (b) the middle area of ZA27; (c) the left border between SSM7075 and ZA27.

However, the $\alpha-\mathrm{Al}$ phase received high activation energy and also caused $\alpha$-Al grains to grow bigger as shown in Figure 4a. Also, such similar result has been mentioned in hua Zhu, Y (2004) [17]. Meanwhile, $\alpha$-Al phase formation is supersaturated to $\alpha^{\prime}$-phase and the combined $\beta^{\prime}+\eta^{\prime}$-phase is supersaturated (grey particles) as shown in Figure 4c. Moreover, the right bonding time and bonding temperature also help the voids disappear. Figure $4 \mathrm{~b}$ shows that, for all combined phases as intermetallic compounds, $\mathrm{MgZn}_{2}$ phase inserted into $\alpha^{\prime}$-phase and the $\beta^{\prime}+\eta^{\prime}$-phase distributed around the bonding zone. These phases supersaturated and completed, leading to good hardness properties. The mechanism of phase formation in the bonding zone is $\alpha-A l+M g Z n_{2}+\beta+\eta$-phase formation, 
and then, isothermal solidification to $\alpha^{\prime}+\mathrm{MgZn}_{2 \text { (precipitation) }}+\beta^{\prime}+\eta^{\prime}$-phase [17]. It must be noted that TLP bonding of SSM7075 aluminum alloy with ZA27 zinc alloy interlayer can speed up the welding process because $\mathrm{Zn}$ and $\mathrm{Al}$ elements are similar main ingredients in both materials. Thus, these affect the diffusion and movement of atoms from higher concentrations to lower concentrations of the elements.

\subsection{Results of Particles in the Bonded Joint by EDX-Ray Spectroscopy}

The micrographic mapping images of the cross-section of the joint bonded by Energy-dispersive $\mathrm{X}$-ray spectroscopy (EDS) from bonding temperature at $540{ }^{\circ} \mathrm{C}$ and bonding time at $120 \mathrm{~min}$ are shown in Figure 5. The results show the distribution of the elements, which are well distributed in the bonding zone and are relevant to the bonding temperature [18]. According to the data from the binary phase diagram in Figure 3, all elements were melted and allowed both $\mathrm{Al}_{2} \mathrm{O}_{3}$ and $\mathrm{ZnO}_{2}$ to freely move to the inner layer and to randomly mix with other elements. This distributing pattern can reduce the number of $\mathrm{Al}_{2} \mathrm{O}_{3}$ and $\mathrm{ZnO}_{2}$ layers clumped in one area, which also promotes the strength of the welded zone.

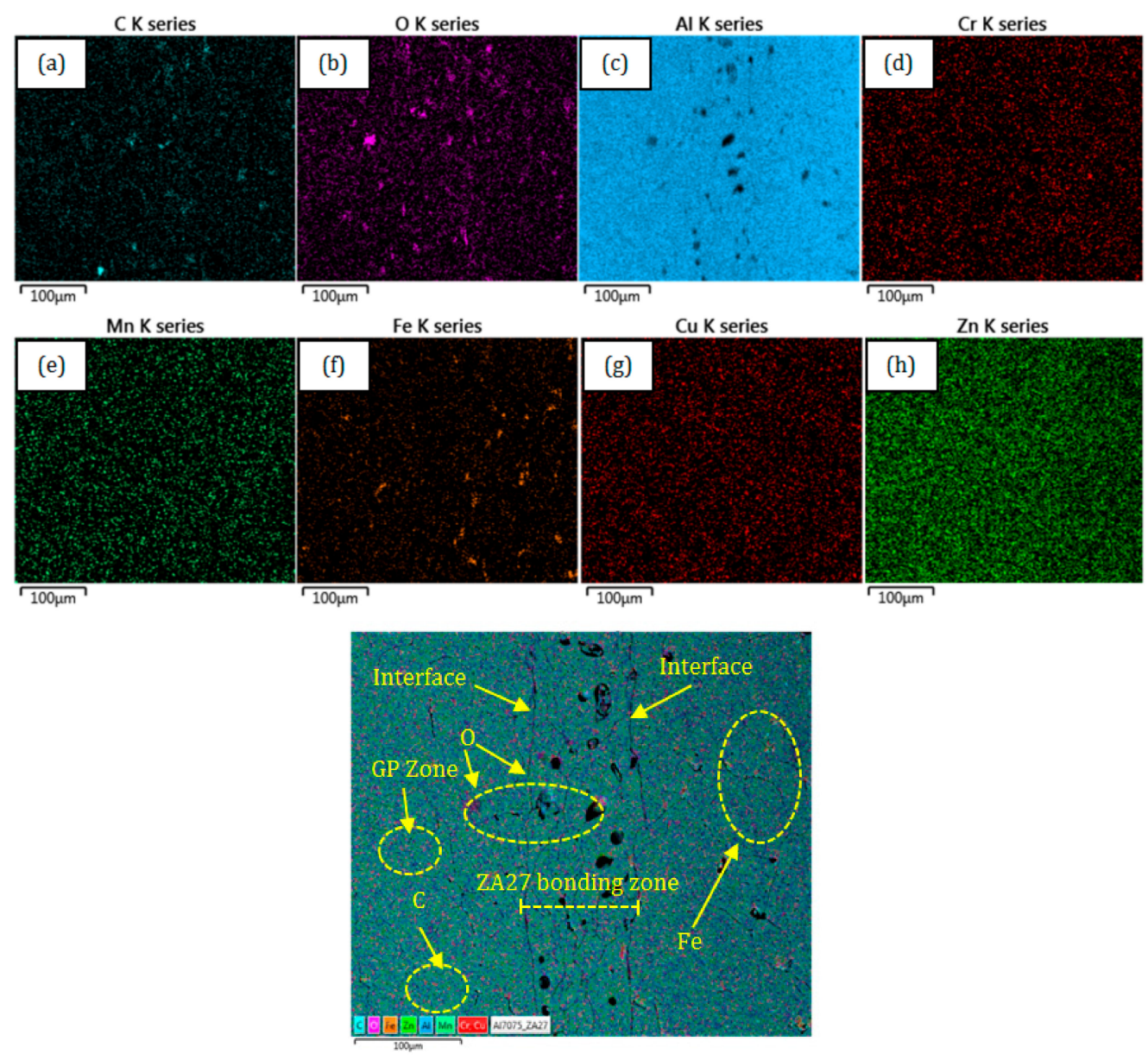

(i)

Figure 5. The micrographic mapping image of the cross-section of the joint bonded by EDX-Ray spectroscopy. (a)-(h) represent the location of each element dispersed around the welding zone by using different filters. These pictures are proportionally the same size as the unfiltered picture on the top. (a) the present of carbon element around welded area; (b) the present of oxygen element around welded area; (c) the present of aluminium element around welded area; (d) the present of chromium element around welded area; (e) the present of manganese element around welded area; (f) the present of iron element around welded area; (g) the present of copper element around welded area; (h) the present of zinc element around welded area; (i) the original picture of welded area without filters. 
The $\mathrm{Cu}$ and $\mathrm{Zn}$ elements have precipitated at high temperatures, as shown in Figure $5 \mathrm{~g}, \mathrm{~h}$. However, the oxide formed by the insertion of moisture will hinder the spread of the elements. It is noteworthy that the oxides are generally distributed along the length of the interface and bonding zone, as shown in Figure 5b. The diffusion mechanism starts to diffuse from the higher concentration to the lower concentration [19], which is evaluated by substituted $C$ elements shown in Figure 5a. The atom of $\mathrm{C}$ elements can insert into the aluminium matrix. Likewise, the $\mathrm{Cr}$, $\mathrm{Mn}$ and Fe elements can precipitate at a high temperature, resulting in good diffusion behavior, as shown in Figure $5 \mathrm{~d}-\mathrm{f}$. After quantitative analysis in the bonding zone, it was found that high concentration of the Al elements was at $72.10 \mathrm{wt} \%$. The results are similarly found that the concentration of elements in the bonding zone came from the alloy elements of welding materials. The $\mathrm{Zn}$ elements at $12.20 \mathrm{wt} \%$, the C elements at $11.30 \mathrm{wt} \%$, the $\mathrm{O}$ elements at $2.30 \mathrm{wt} \%$, and the $\mathrm{Cu}$ elements at $1.00 \mathrm{wt} \%$ are respectively shown in Figure 6. However, for bonding temperature as a result of the mixed-element formation of the intermetallic compound, this significantly increased the mechanical properties. The elements will be transformed in Guinier-Preston (GP) zones (The GP zones are the meta-stable phases or precipitates) [17]. Thus, it can be seen that the bonding time and bonding temperature can influence the TLP bonding process of SSM7075 aluminum alloy using ZA27 zinc alloy interlayer.

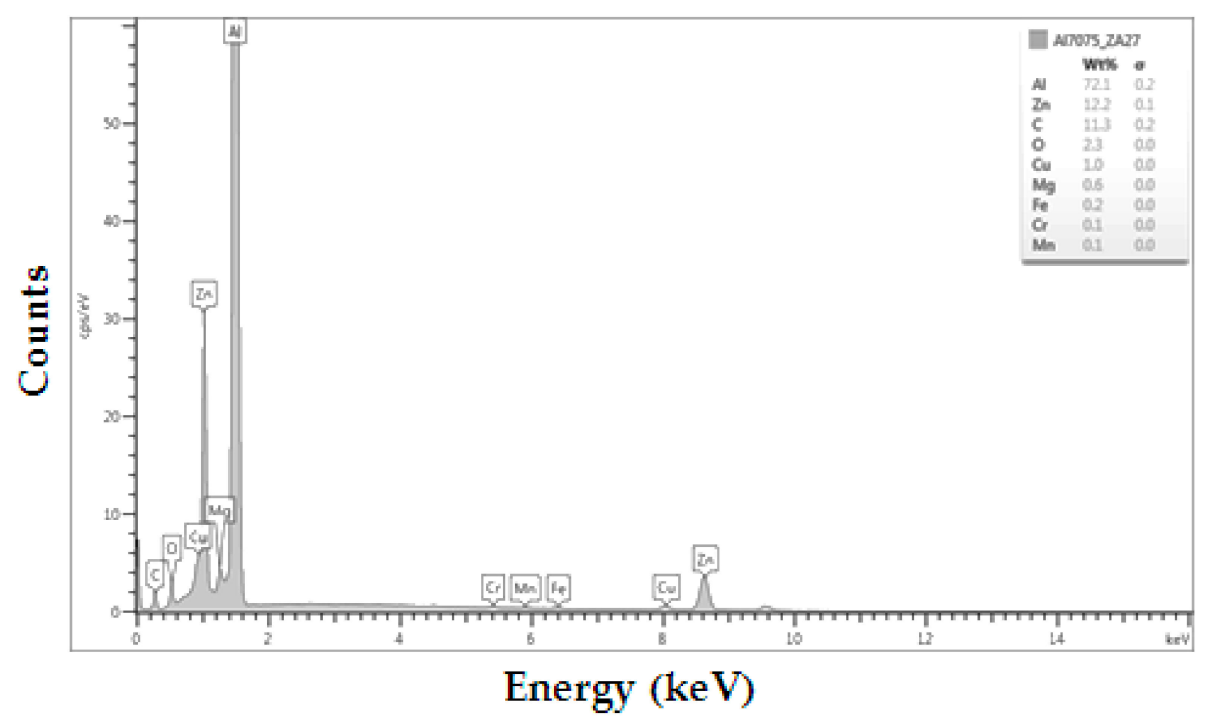

Figure 6. EDX-Ray analysis for distribution of elements.

\subsection{Results of Bonding Strength of Joint}

Figure 7 shows the joint bonding strengths for the relationship between bonding temperature and bonding time. All samples in this experiment were cut at the bonded joint and the comparison of bonding strengths found that the increase of bonding temperature and bonding time tended to make better bonding strength. For example, at a bonding temperature of $540{ }^{\circ} \mathrm{C}$ and bonding time of $120 \mathrm{~min}$, an average bonding strength value was $17.44 \mathrm{MPa}$. On the other hand, lower bonding temperature and bonding time caused lower bond strength. The void after the TLP bonding process caused different bonding strengths. Moreover, the crack or shrinkage at the liquid state of $\mathrm{Zn}, \mathrm{Al}$ and other element could result in lower bonding strength [20]. The bonding temperature of $480^{\circ} \mathrm{C}$ and bonding time of $30 \mathrm{~min}$ resulted in lower bonding strength value at $2.27 \mathrm{MPa}$, in which the joint efficiency was lower than the base metal of SSM7075 aluminium alloys (207.08 MPa) or base metal ZA27 zinc alloy (125.22 MPa). However, when the bonding time increases, it leads to the addition of bonding strength explicitly [21]. The bonding time from 60 to $120 \mathrm{~min}$ with the bonding temperature of $480^{\circ} \mathrm{C}$ significantly increased bonding strength, which were 5.54, 8.95 and $9.28 \mathrm{MPa}$, respectively. It was also found that when bonding time and bonding temperature increased, the formation of the complete 
intermetallic compounds were observed, which were $\eta(\mathrm{Zn}-\mathrm{Al}-\mathrm{Cu}), \beta\left(\mathrm{A}_{12} \mathrm{Mg}_{3} \mathrm{Zn}_{3}\right), \mathrm{T}^{\prime}\left(\mathrm{Zn}_{10} \mathrm{Al}_{35} \mathrm{Cu}_{55}\right)$ and $\mathrm{MgZn}_{2}$ phase especially in the high bonding strength area $[14,15]$. For the bonding temperature at $540{ }^{\circ} \mathrm{C}$ and bonding time from 30 to $90 \mathrm{~min}$, it can be seen that the average bonding strengths were 2.31, 5.61 and $11.93 \mathrm{MPa}$ respectively. It is noteworthy that the bonding time from $60 \mathrm{~min}$ or more significantly increased bonding strength. This is because the diffusion mechanism and activating thermal energy led to increases and a better bonding area. The TLP bonding process is a good bonding technique for the surface oxide film elimination when compared to other traditional diffusion bonding processes. For the elimination of surface oxide film there is a huge need for a diffusion process because it will affect the mechanism of atomic motion. The surface oxide film is a problem for many researchers. Therefore, the argon atmospheric chamber for this type of diffusion bonding has significant implications in solving these problems [12].

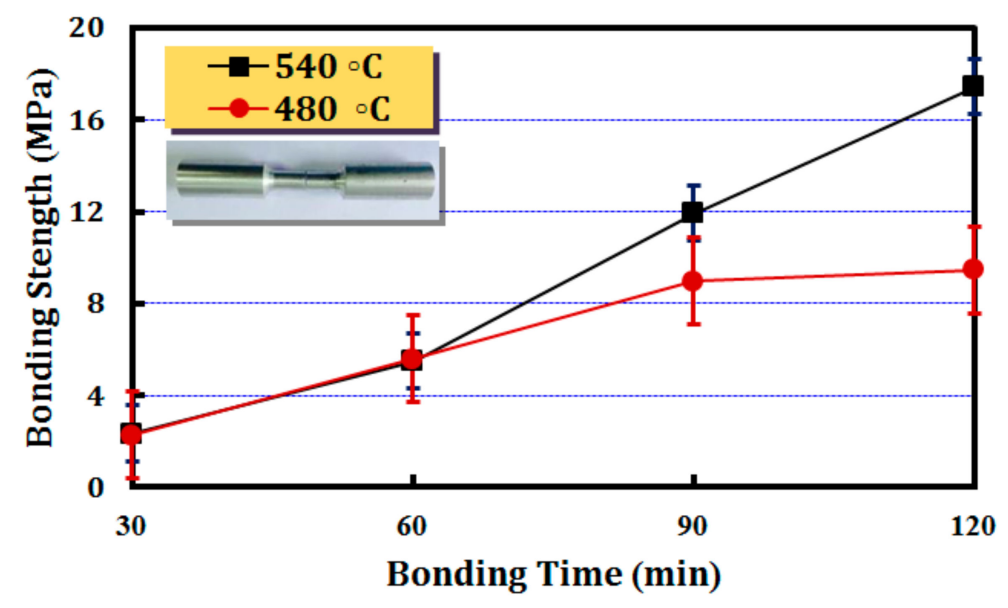

Figure 7. Bonding strength with TLP bonding of SSM 7075 aluminum alloy using ZA27 zinc alloy Interlayer.

\subsection{Results of Vickers Hardness}

Figure 8 shows microhardness profiles ( $0.2 \mathrm{~mm}$ away from the bonding zone). The results show that hardness values from the bonding zone are higher than the hardness values of base materials (as cast). This is because the increasing thermal temperature during the TLP bonding process allowed elements to precipitate and become an intermetallic compound. The hardening mechanism from the $\mathrm{MgZn}_{2}$ phase received activating energy and caused atoms to move and dissolve, yielding the improved microstructure of materials. The higher bonding time and bonding temperature potentially generated higher hardness and reduced defects [22]. For example, bonding time at $120 \mathrm{~min}$ and bonding temperature at $540{ }^{\circ} \mathrm{C}$ resulted in the average hardness of $87.67 \mathrm{HV}$, as shown in Figure $8 \mathrm{~b}$, which was the highest hardness property among all conditions. Moreover, higher bonding time and bonding temperature in the TLP bonding process can eliminate the oxidation process, as a result of a semi-solid state of ZA27 zinc alloy during the TLP bonding process. The long bonding time affects the precipitation of elements to become a complete-intermetallic compound. $\mathrm{Al}, \mathrm{Zn}, \mathrm{Cu}, \mathrm{Cr}, \mathrm{Mg}$ and $\mathrm{Fe}$ were interchanged or exchanged and subsequently formed various types of intermetallic compounds such as $\eta(\mathrm{Zn}-\mathrm{Al}-\mathrm{Cu}), \beta\left(\mathrm{Al}_{2} \mathrm{Mg}_{3} \mathrm{Zn}_{3}\right), \mathrm{T}^{\prime}\left(\mathrm{Zn}_{10} \mathrm{Al}_{35} \mathrm{Cu}_{55}\right)$ and $\mathrm{MgZn}_{2}$ phase [14,15]. On the other hand, lower bonding time and bonding temperature do not support hardness properties [2]. For example, bonding time at 30 and $60 \mathrm{~min}$ with bonding temperature at $480^{\circ} \mathrm{C}$ caused the average hardness values at 73.04 and at $76.33 \mathrm{HV}$, as shown in Figure 8a. The hardness values were roughly the same in all the areas at $480^{\circ} \mathrm{C}$. On the other hand, it is noteworthy that high hardness was found in the bonding zone with bonding temperature at $540{ }^{\circ} \mathrm{C}$ when compared with other regions. Therefore, this may yield some benefits to other intense-use application. This is because the ZA27 zinc alloys were in a semi-solid state and they have good solubility in the liquid state, which well diffuses to other atoms. 
Thus, recrystallization of the microstructure in the bonding zone or other areas can be the result from the bonding time and bonding temperature from the TLP bonding process.

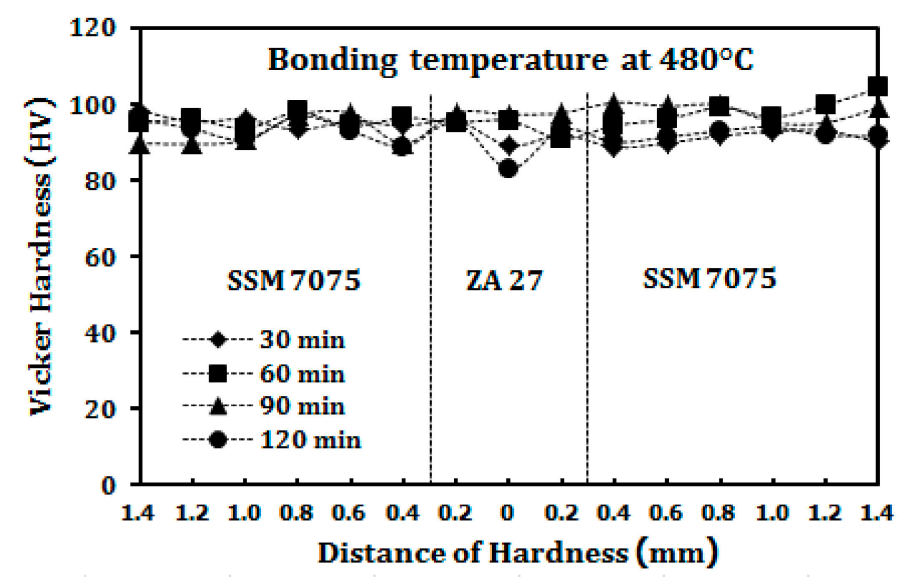

(a)

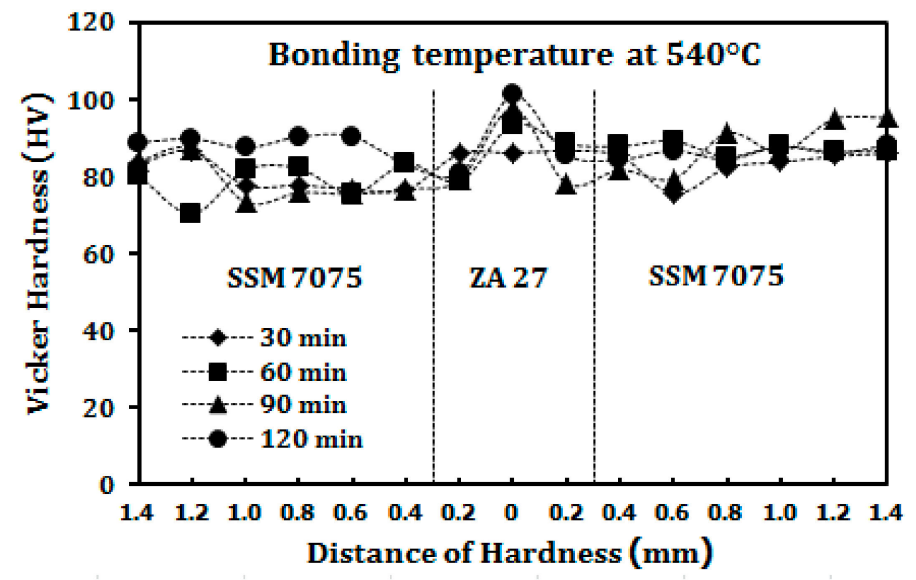

(b)

Figure 8. Microhardness profile at the bonding zone with bonding times of 30, 60, 90 and 120 min and bonding temperature at (a) $480{ }^{\circ} \mathrm{C}$ and (b) $540{ }^{\circ} \mathrm{C}$.

\subsection{Analysis of Bonding Strength Data Using Statistical Method Analysis of Model Accuracy}

General full factorial design was used in this experiment. Bonding time and bonding temperature are two factors that unequally affected the results of samples shown in Table 2.

Table 2. Factors and levels in experiments.

\begin{tabular}{ccccc}
\hline Factors & \multicolumn{4}{c}{ Levels } \\
\hline Bonding time (min) & 30 & 60 & 90 & 120 \\
Bonding temperature (degree celsius) & 480 & 540 & - & - \\
\hline
\end{tabular}

After statistical data analysis of general full factorial design model [23-25], the results of bonding strength were analyzed in 3 aspects: (1) normal distribution analysis, (2) randomized distribution analysis and (3) variance analysis around zero, as shown in Figure 9. Thus, the results from this experiment are eligible for further analysis. 


\section{Residual Plots for Bonding strength}
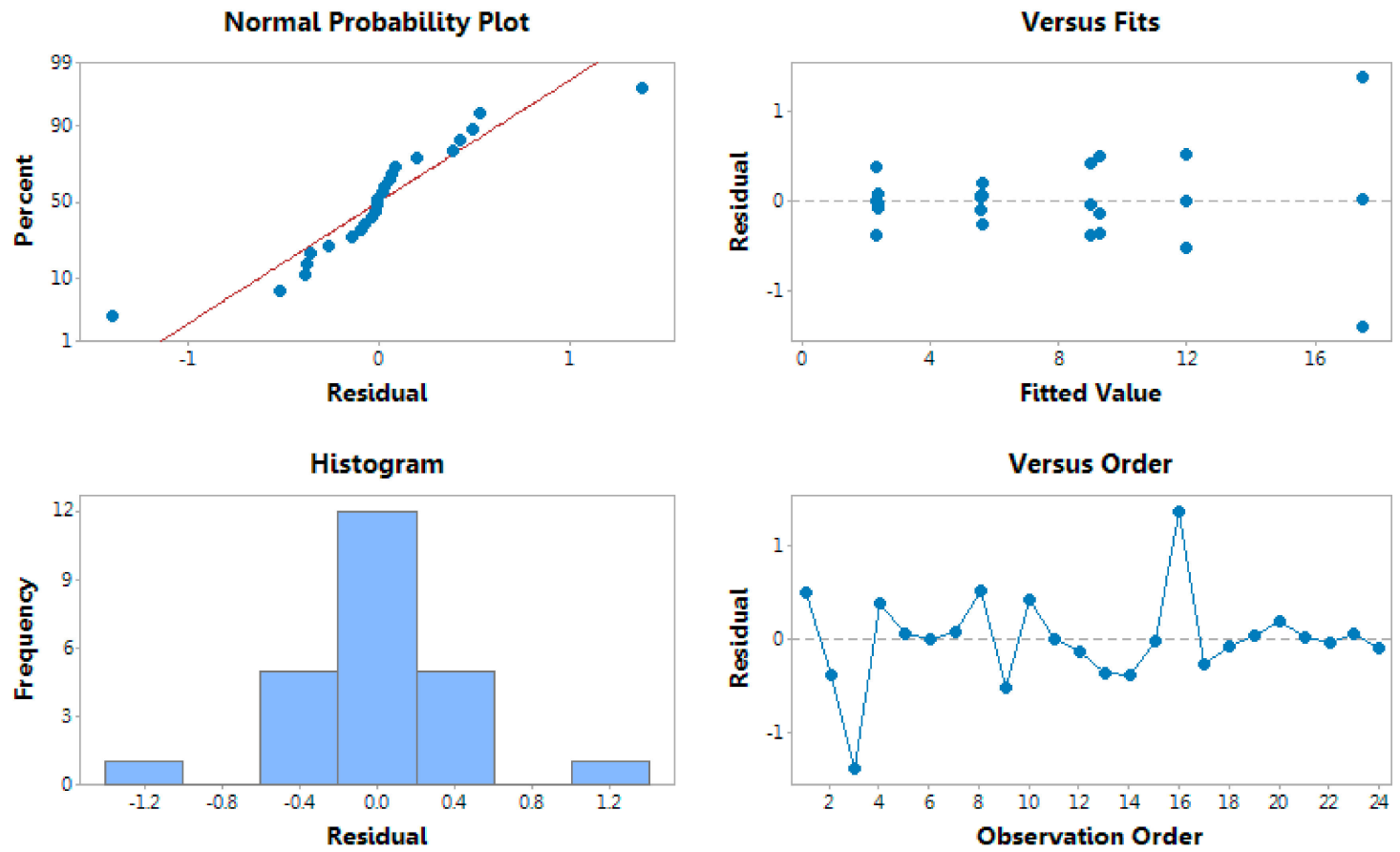

Figure 9. Statistical data analysis of general full factorial design model.

According to Analysis of Variance (ANOVA) analysis shown in Table 3, it was found that both bonding time and bonding temperature directly affected the bonding strength with $\mathrm{R}^{2}=99.01 \%$. As shown in Figure 10, it was found that when the bonding time was increased from 30 to $60 \mathrm{~min}$, there was no bonding strength difference in both bonding temperature conditions. However, when the bonding time was increased from 60 to $90 \mathrm{~min}$, the value of bonding strength at $540{ }^{\circ} \mathrm{C}$ was a little higher than what was at $480^{\circ} \mathrm{C}$. Interestingly, when the bonding time was increased from 90 to $120 \mathrm{~min}$, the value of bonding strength at $540{ }^{\circ} \mathrm{C}$ was a lot higher than what was at $480{ }^{\circ} \mathrm{C}$. Besides, it was noticed that the value of bonding strength at $480^{\circ} \mathrm{C}$ started to flatten out after $90 \mathrm{~min}$ of bonding time.

Table 3. Analysis of Variance (ANOVA) analysis for bonding strength test.

\begin{tabular}{cccccc}
\hline Source & DF & Adj SS & Adj MS & F-Value & $p$-Value \\
\hline Bonding Time (Btim) & 3 & 438.976 & 146.325 & 424.36 & 0.000 \\
Bonding Temperature (Btem) & 1 & 47.489 & 47.489 & 137.72 & 0.000 \\
Btim $\times$ Btem & 3 & 65.853 & 21.951 & 63.66 & 0.000 \\
Error & 16 & 5.517 & 0.345 & - & - \\
Total & 23 & 557.835 & - & - & - \\
\hline \multicolumn{4}{c}{$\mathrm{S}=0.587 ; \mathrm{R}-\mathrm{Sq}=99.01 \%$; R-Sq (adj) $=98.58 \%}$.
\end{tabular}

As shown in Figure 11, it was found that when the bonding time was increased from $30 \mathrm{~min}$ to $120 \mathrm{~min}$, the bonding strength also increased. Likewise, when the bonding temperature was increased from $480{ }^{\circ} \mathrm{C}$ to $540{ }^{\circ} \mathrm{C}$, the bonding strength also increased. 


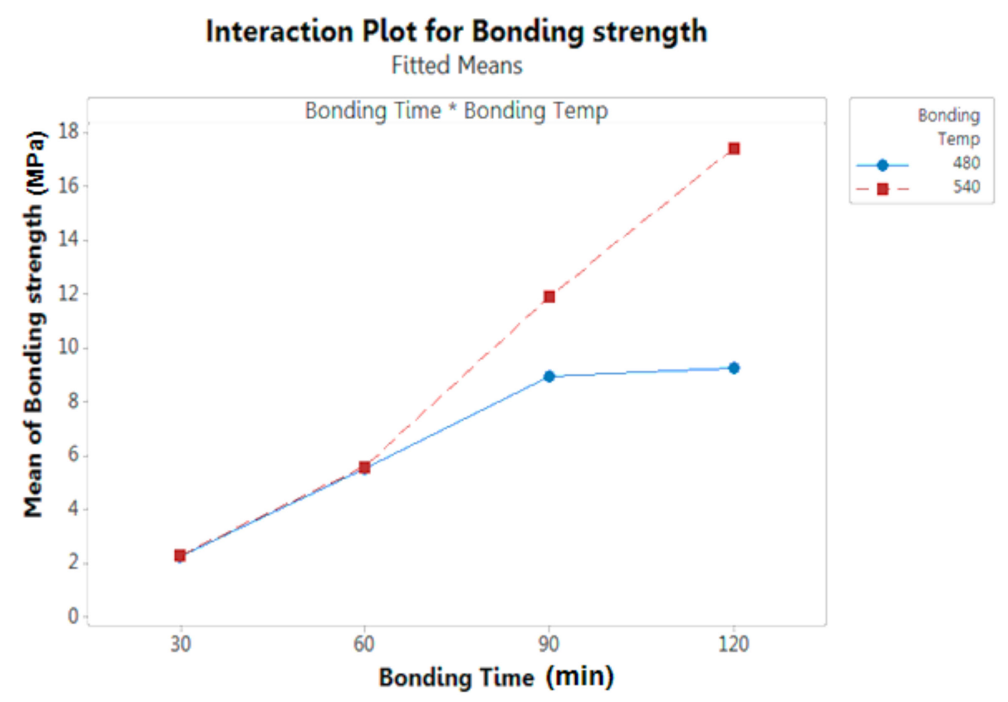

Figure 10. The effect of two factors that influence the bonding strength.

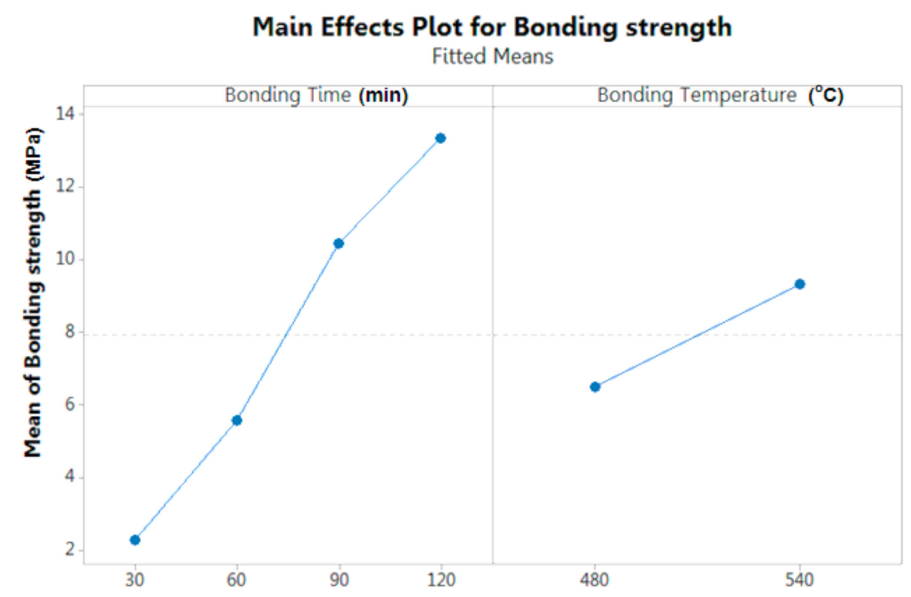

Figure 11. The effect of two main factors to the bonding strength.

The amount of heat that occurred during the welding process directly affects the bonding strength. This heat is caused from previously mentioned factors which can be classified into 3 stages. For the first stage, the amounts of heat that occurred during 30 to $60 \mathrm{~min}$ of bonding time was roughly the same. For the second stage, during 60 to $90 \mathrm{~min}$ of bonding time, the amount of heat at bonding temperature $540{ }^{\circ} \mathrm{C}$ was a little higher than at $480{ }^{\circ} \mathrm{C}$. For the last stage, there was the highest difference in the amount of heat that occurred during $90 \mathrm{~min}$ to $120 \mathrm{~min}$ of bonding time. Therefore, it can be clearly concluded and formulate an equation for bonding strength regression shown in Equation (2).

Bonding strength $=-25.52+0.1269$; bonding time +0.0469 Bonding temperature

\section{Conclusions}

In this work, the joining of similar SSM7075 aluminium alloys was achieved by TLP bonding process using ZA27 zinc alloy as an interlayer. To evaluate the results achieved, it is concluded that:

The different bonding time and different bonding temperature in the TLP bonding process can influence the microstructure recrystallization process in the bonding zone, which triggers the precipitation process and the formation of intermetallic compounds- $\eta(\mathrm{Zn}-\mathrm{Al}-\mathrm{Cu}), \beta\left(\mathrm{Al}_{2} \mathrm{Mg}_{3} \mathrm{Zn}_{3}\right)$, $\mathrm{T}^{\prime}\left(\mathrm{Zn}_{10} \mathrm{Al}_{35} \mathrm{Cu}_{55}\right)$ and $\mathrm{MgZn}$, phase respectively. The different intermetallic compounds directly affect the mechanical property with an average maximum bonding strength value at $17.44 \mathrm{MPa}$ for bonding 
temperature at $540{ }^{\circ} \mathrm{C}$ and bonding time for $120 \mathrm{~min}$. Meanwhile, average hardness value was $87.67 \mathrm{HV}$ from the same parameters. Moreover, according to statistical data analysis of the general full factorial design model, the coefficient of determination for the bonding strength result was $99.1 \%$. The estimated bonding strength values and the relationship between bonding time and bonding temperature can be expressed as: fitted bonding strength $=-25.52+0.1269$; bonding time +0.0469 bonding temperature

Author Contributions: Conceptualization, C.M.; Methodology, C.M.; Software, C.M.; Formal Analysis, C.M. and S.C.; Investigation, Y.D.; Data Curation, C.M.; Writing-Original Draft Preparation, C.M.; Writing-Review \& Editing, C.M. and D.M.; Supervision, Y.D.; Project Administration, C.M.; Funding Acquisition, C.M.

Funding: This research was funded by National Research Council of Thailand grant number 06/2560.

Acknowledgments: The authors would like to thank Department of Engineering, Faculty of Industrial Technology, Songkhla Rajabhat University and Department of Industrial Engineering, Faculty of Engineering, Rajamangala University of Technology Srivijaya University in Thailand.

Conflicts of Interest: The authors declare no conflict of interest.

\section{References}

1. Nami, H.; Halvaee, A.; Adgi, H. Transient liquid phase diffusion bonding of $\mathrm{Al} / \mathrm{Mg}_{2} \mathrm{Si}$ metal matrix composite. Mater. Des. 2011, 32, 3957-3965. [CrossRef]

2. Jin, Y.J.; Khan, T.I. Effect of bonding time on microstructure and mechanical properties of transient liquid phase bonded magnesium AZ31 alloy. Mater. Des. 2012, 38, 32-37. [CrossRef]

3. Park, M.S.; Gibbons, S.L.; Arroyave, R. Phase-field simulations of intermetallic compound growth in $\mathrm{Cu} / \mathrm{Sn} / \mathrm{Cu}$ sandwich structure under transient liquid phase bonding conditions. Acta Mater. 2012, 60, 6278-6287. [CrossRef]

4. Cooke, K.O.; Khan, T.I.; Oliver, G.D. Transient liquid phase diffusion bonding Al-6061 using nano-dispersed Ni coatings. Mater. Des. 2012, 33, 469-475. [CrossRef]

5. Zhao, L.Z.; Jiao, Y.; Zhao, M.J.; Zhang, J. Investigation on in situ $\mathrm{Al}_{0.5} \mathrm{FeSi}_{0.5} / \mathrm{Al}$ composites prepared by transient liquid phase sintering. Mater. Des. 2014, 59, 70-75. [CrossRef]

6. Kenevisi, M.S.; Mousavi Khoie, S.M. An investigation on microstructure and mechanical properties of Al7075 to Ti-6Al-4V Transient Liquid Phase (TLP) bonded joint. Mater. Des. 2012, 38, 19-25. [CrossRef]

7. Sayyedain, S.S.; Salimijazi, H.R.; Toroghinejad, M.R.; Karimzadeh, F. Microstructure and mechanical properties of transient liquid phase bonding of $\mathrm{Al}_{2} \mathrm{Op}_{3} / \mathrm{Al}$ nanocomposite using copper interlayer. Mater. Des. 2014, 53, 275-282. [CrossRef]

8. Zhang, G.; Zhang, J.; Pei, Y.; Li, S.; Chai, D. Joining of $\mathrm{Al}_{2} \mathrm{O}_{3} \mathrm{p} / \mathrm{Al}$ composites by transient liquid phase (TLP) bonding and a novel process of active-transient liquid phase (A-TLP) bonding. Mater. Sci. Eng. A 2008, 488, 146-156. [CrossRef]

9. Kenevisi, M.S.; Mousavi Khoie, S.M.; Alaei, M. Microstructural evaluation and mechanical properties of the diffusion bonded Al/Ti alloys joint. Mech. Mater. 2013, 64, 69-75. [CrossRef]

10. Meengam, C.; Chainarong, S.; Muangjunburee, P. Friction welding of semi-solid metal 7075 aluminum alloy. Mater. Today Proc. 2017, 4, 1303-1311. [CrossRef]

11. Dezellus, O.; Andrieux, J.; Bosselet, F.; Sacerdote-Peronnet, M.; Baffie, T.; Hodaj, F.; Eustathopoulos, N.; Viala, J.C. Transient liquid phase bonding of titanium to aluminium nitride. Mater. Sci. Eng. A 2008, 495, 254-258. [CrossRef]

12. Maity, J.; Pal, T.K.; Maiti, R. Transient liquid phase diffusion bonding of $6061-15$ wt \% SiCp in argon environment. J. Mater. Process. Technol. 2009, 209, 3568-3580. [CrossRef]

13. Mohamed, I.S.; Tahir, I.K.; Hans, J.R. Transient liquid phase bonding of AA-6063 to UNS S32304 using Cu interlayer. Proc. Chem. 2016, 19, 517-524.

14. He, Z.; Su, X.; Peng, H.; Liu, Y.; Wu, C.; Wang, J. $600{ }^{\circ} \mathrm{C}$ isothermal section of the Al-Cr-Zn ternary phase diagram. J. Alloys Compd. 2015, 649, 1239-1245. [CrossRef]

15. Liang, S.-M.; Schmid-Fetzer, R. Thermodynamic assessment of the Al-Cu-Zn system, Part III: Al-Cu-Zn ternary system. Calphad 2016, 52, 21-37. [CrossRef]

16. Mazar Atabaki, M.; Idris, J. Low-temperature partial transient liquid phase diffusion bonding of $\mathrm{Al} / \mathrm{Mg}_{2} \mathrm{Si}$ metal matrix composite to AZ91D using Al-based interlayer. Mater. Des. 2012, 34, 832-841. [CrossRef] 
17. Zhu, Y.h. General rule of phase decomposition in Zn-Al based alloys (II) on effects of external stresses on phase transformation. Mater. Trans. 2004, 45, 3083-3097. [CrossRef]

18. Seyyed Afghahi, S.S.; Ekrami, A.; Farahany, S.; Jahangiri, A. Fatigue properties of temperature gradient transient liquid phase diffusion bonded Al7075-T6 alloy. Trans. Nonferrous Met. Soc. China 2015, 25, 1073-1079. [CrossRef]

19. Dunyakul, Y.; Meengam, C.; Maunkhaw, D.; Chainarong, S. Evaluation of microstructure and mechanical properties in dissimilar joint of SSM7075 with SSM356 aluminum alloy using diffusion bonding. Eng. J. 2016, 20, 135-144. [CrossRef]

20. AlHazaa, A.; Khan, T.I.; Haq, I. Transient liquid phase (TLP) bonding of Al7075 to Ti-6Al-4V alloy. Mater. Charact. 2010, 61, 312-317. [CrossRef]

21. Bosco, N.S.; Zok, F.W. Strength of joints produced by transient liquid phase bonding in the Cu-Sn system. Acta Mater. 2005, 53, 2019-2027. [CrossRef]

22. Jalilvand, V.; Omidvar, H.; Rahimipour, M.R.; Shakeri, H.R. Influence of bonding variables on transient liquid phase bonding behavior of nickel based superalloy IN-738LC. Mater. Des. 2013, 52, 36-46. [CrossRef]

23. Ryan, T.P. Modern Engineering Statistics, 1st ed.; John Wiley \& Sons Inc.: New York, NY, USA, 2007; pp. 140-189.

24. Montgomery, D.C. Designing and Analysis of Experiments, 8th ed.; John Wiley \& Sons Inc.: New York, NY, USA, 2000; pp. 24-146.

25. Box, G.E.P.; Draper, N.R. Empirical Model-Building and Response Surface, 1st ed.; John Wiley \& Sons Inc.: New York, NY, USA, 1987; pp. 52-189.

(C) 2018 by the authors. Licensee MDPI, Basel, Switzerland. This article is an open access article distributed under the terms and conditions of the Creative Commons Attribution (CC BY) license (http:// creativecommons.org/licenses/by/4.0/). 